\title{
Genealogias Políticas do Judiciário
}

\author{
Ricardo Costa de Oliveira
}

\begin{abstract}
Resumo: Investigamos as genealogias políticas de alguns membros do poder judiciário com destaque recente. Pesquisamos as origens familiares, as narrativas genealógicas, os valores profissionais, sociais e políticos de membros do Tribunal Regional Federal da $4^{\text {a }}$ Região, especialmente o presidente, desembargador Carlos Eduardo Thompson Flores Lenz, os desembargadores João Pedro Gebran Neto, Victor Luis dos Santos Laus e Leandro Paulsen. Analisamos as biografias, formação educacional, vínculos sociais e a genealogia destes atores, como mais um elemento explicativo dos interesses, comportamentos e habitus de classe. Complementamos a investigação com a observação de algumas outras redes familiares no judiciário do Paraná. A conclusão é a visualização de uma prosopografia familiar conservadora e corporativista instalada no sistema judicial brasileiro, com grandes consequências políticas na atual conjuntura. As nossas pesquisas sempre revelam que no Brasil e no Paraná, em parte central, o poder judiciário é hereditário e familiar, bem como as mentalidades e a cultura política.
\end{abstract}

Palavras-chave: Genealogia. Judiciário. Classe Dominante. Elites Jurídicas.

\section{Political Genealogies of the Judiciary}

\begin{abstract}
We investigate the political genealogies and social networks of some members of the judiciary with recent political prominence.
\end{abstract}

Key words: Genealogy. Judiciary. Ruling Class. Judicial Elites.

*Recebido em 20/06/2018.

*Aceito em 26/06/2018.

Investigamos atores no sistema judicial, poder judiciário, ministério público e a existência de relações familiares, cônjuges e parentescos político-jurídicos. Levantamento objetivo sobre a presença de relações familiares dentro do Estado e de escritórios de advocacia. O sistema judicial apresenta múltiplas conexões e parentescos políticos. Analisamos alguns dos principais atores em dois circuitos político-jurídicos: a operação Lava Jato e o tratamento de reivindicações dos professores na justiça do Paraná.

\footnotetext{
${ }^{1}$ Professor Associado do Departamento de Sociologia e do Programa de pós-Graduação em Sociologia da Universidade Federal do Paraná - UFPR. Coordenador do NEP (Núcleo de Estudos Paranaenses). Contado: rco2000@uol.com.br
} 
A discussão sobre a existência de redes sociais e familiares é debatida no próprio discurso de membros das altas cortes do judiciário brasileiro: "O ministro do STF (Supremo Tribunal Federal) Gilmar Mendes afirmou que a ordem prisão do juiz Sérgio Moro para o expresidente Luiz Inácio Lula da Silva foi "absurda", porque havia espaço para novo recurso ao Tribunal Regional Federal da $4^{\mathrm{a}}$ Região, e que faltou "pedigree" a ministros indicados por Lula para integrar o próprio Supremo. Segundo ele, a situação atual no País equivaleria a um "despotismo judicial". "Estamos vivendo uma "Prokuratura", disse ele, em Lisboa. O termo russo refere-se ao período em que a então União Soviética vivia sob a subordinação do Soviete Supremo, o poder legislativo soviético. "A prisão de Lula é absurda, fruto do autoritarismo desse punitivismo processual hoje em voga no País. Os recursos [que Lula pode apresentar à Justiça] ainda não se esgotaram e já se precipita a prisão!", afirmou.",2

\section{O Circuito da Operação Lava Jato e suas redes familiares, sociais e político-jurídicas ${ }^{3}$}

\section{1 - Sérgio Fernando Moro}

Sérgio Moro foi indicado pelo ex-reitor da Universidade de Maringá, Neumar Adélio Godoy, para um dos primeiros empregos em escritório de advocacia, de direito tributário, com Irivaldo de Souza, um dos principais na região de Maringá e bastante envolvido com a política local. Neumar Godoy já apresentava conexões familiares e pessoais com os pais de Sérgio Moro, Dalton e Odete, de acordo com várias fontes ${ }^{4}$. Neumar Godoy pode ter sido considerado um reitor no campo político da direita e mesmo no autoritarismo no final da ditadura. Em 1981 ocorreu um episódio afastando universitários do DCE e o Deputado Federal, Heitor Furtado, solicitou a destituição do reitor da UEM $^{5}$. Neumar Godoy também foi posteriormente secretário municipal de Sílvio Barros II.

"Recomendado por Neumar Godoy, ex-reitor da UEM, Sérgio Moro foi contratado por Irivaldo de Souza para estagiar em um escritório de direito tributário, em 1994"6.

Carlos Zucolotto Junior, advogado, amigo e padrinho de casamento de Moro ${ }^{7}$.

\footnotetext{
${ }^{2}$ http://www.osul.com.br/o-ministro-do-supremo-gilmar-mendes-diz-que-a-prisao-de-lula-e-absurda-eresponsabiliza-o-pt/

${ }^{3}$ Outro texto do nosso grupo é a "Prosopografia Familiar da Operação Lava Jato e do Ministério Temer". https://revistas.ufpr.br/nep/article/view/55093/33455)

${ }^{4}$ Luiz Scarpino. Sérgio Moro: o homem, o juiz e o Brasil. 2016. Editora Novo Conceito.

https://www.diariodocentrodomundo.com.br/retrato-do-juiz-sergio-moro-quando-jovem-por-renan-antunes-deoliveira/

${ }^{5}$ Diário do Paraná. Página 3 - 28/3/1981 e página 2 - 12/4/1981

${ }^{6}$ (Sérgio Moro: o homem, o juiz e o Brasil. Por Luiz Scarpino).
} 
A família Moro possuiu um desembargador no Tribunal de Justiça do Paraná, Hildebrando Moro, primo do pai do juiz Sérgio Moro ${ }^{8}$.

A esposa Rosangela Maria Wolff de Quadros Moro, advogada. Procuradora da Federação das APAEs do Estado do Paraná. Uma das principais lideranças políticas no movimento das APAES foi o ex-senador Flávio Arns, de tradicional família religiosa e política. O sobrinho de Arns é o advogado Marlus Arns de Oliveira, filho do falecido procurador Luiz Carlos de Oliveira e criador de um dos mais prestigiados cursos para preparatórios nas carreiras e concursos jurídicos, o Centro de Estudos Jurídicos Luiz Carlos. Marlus Arns apresenta grande destaque no campo advocatício das delações mais caras da operação Lava Jato. Rosangela Maria descende da grande família política Macedo do Paraná. Prima dos desembargadores Haroldo Bernardo da Silva Wolff e Fernando Paulino da Silva Wolff Filho. Prima do empresário Luiz Fernando Wolff de Carvalho, Triunfo e Econorte, construtora e do ramo de pedágios ${ }^{9}$. A esposa de Moro, Rosangela Maria Wolff de Quadros Moro, é prima distante de Rafael Greca de Macedo e de Beto Richa. A importância da família Macedo está presente no empresariado, na história da Associação Comercial do Paraná, nos inúmeros desembargadores e presidentes do Tribunal de Justiça (muitas vezes referidos como a poderosa "macedônia”), na universidade, na prefeitura e em várias outras instituições.

\section{2 - Carlos Fernando dos Santos Lima}

Carlos Fernando dos Santos Lima, procurador. Filho do procurador Osvaldo dos Santos Lima. Deputado Estadual pela ARENA. Presidente da Assembleia Legislativa do Paraná, ALEP, em 1973.

"A cerimônia de posse foi presidida pelo procurador-geral de Justiça, Gilberto Giacoia, que destacou a história da família Santos Lima: o pai Osvaldo (em memória) e o irmão Luiz José foram procuradores de Justiça do MP-PR, e o irmão Carlos Fernando é procurador da República e atua na força-tarefa da Lava Jato, do MPF. "Santos Lima é quase uma marca registrada de combate à corrupção", disse. O procurador-geral citou, ainda, o poema "Caminante no hay camino", de Antonio Machado, para falar da trajetória ministerial do novo procurador. "Foi assim, caminhando, fazendo o seu próprio caminho, que ao longo

\footnotetext{
${ }^{7}$ https://noticias.uol.com.br/politica/ultimas-noticias/2017/08/27/acusacao-de-advogado-contra-moro-e-caso-deprisao-preventiva-diz-critico-da-lava-jato.htm

${ }^{8}$ https://www.geni.com/people/Edmundo-Moro/6000000040802517077

${ }^{9}$ Genealogia de Manoel Ribeiro de Macedo. João Noel Azevedo Macedo e Enólia Macedo Bacellar. 1998. https://jornalggn.com.br/noticia/a-lava-jato-e-a-influente-republica-dos-arns
} 
desses anos Paulo Ovídio foi construindo um nome que dispensa qualquer apresentação. Nós falamos, aqui, da trajetória de um colega que muito nos orgulha". "Feliz o homem que a história chega antes dele. E a sua, no Colégio de Procuradores, chegou bem antes de você, Paulo", destacou. ${ }^{10,}$

Outro irmão foi professor da Universidade Federal do Paraná, Osvaldo dos Santos Lima.

Carlos Fernando dos Santos Lima foi casado com Vera Lucia Ribas de Macedo, funcionária do Banestado em Foz do Iguaçu.

O avô paterno, Luiz dos Santos Lima, também foi juiz e apresenta uma genealogia bastante tradicional na Lapa. Genealogia Paranaense. Volumes I-543 e V-437

\section{3 - Deltan Martinazzo Dallagnol}

Deltan Martinazzo Dallagnol, procurador. Filho do procurador Agenor Dallagnol. "Seu pai, Agenor Dallagnol, procurador de Justiça aposentado do Paraná, foi seu advogado na causa de ingresso na carreira de procurador federal ${ }^{11}$,

Deltan Dallagnol casou com Fernanda Mourão Ribeiro. "No quarto ano da faculdade - o mesmo em que, numa viagem dos "napas" para surfar em Mariscal, Santa Catarina, conheci Fernanda Ribeiro, que se tornaria minha esposa oito anos depois"12.

Fernanda Mourão Ribeiro Dallagnol. Sócia da Sanegraph ${ }^{13}$ desde 2012, Bacharel em Direito pela Pontifícia Universidade Católica do Paraná, 2007. OAB, 2007. Especialização em Direito Administrativo pelo instituto Damásio de Jesus, 2008. Mestre em Business Management pela Harvard University (USA), 2016. A Sanegraph tem como sócio Leandro Martini Ribeiro, Felipe Mourão Ribeiro. Tem como alguns dos clientes: EMASA BALN. CAMBORIU - SC, ACQUA \& URBE ENG. - RJ, UFC ENG. - BA, GEOTÉCNICA - RJ, MINISTÉRIO DA AERONÁUTICA - RJ, SANEPAR - PR, FUNDAÇÃO NACIONAL DE SAÚDE, CAGECE - CE, SANED - SP, TECNOSAN - SP, UNIVERSIDAD NACIONAL DE MISIONES - AR, ENGESOFT - CE, HOLON ENG. - BA, DORÉ ENG. - PR. "A Sanegraph Ltda atua desde 1997 no mercado de Saneamento e Meio Ambiente, com softwares para elaboração de projetos técnicos de engenharia e sistemas para gestão de

\footnotetext{
${ }^{10} \mathrm{http} / / / \mathrm{www} \cdot$ comunicacao.mppr.mp.br/modules/noticias/article.php?storyid=5910

${ }^{11} \mathrm{http}$ ://www3.redetv.uol.com.br/blog/reinaldo/dallagnol-se-fez-procurador-contra-o-que-diz-a-lei-e-ficou-nabase-da-teoria-do-fato-consumado/

http://www.mpf.mp.br/pr/sala-de-imprensa/noticias-pr/ingresso-no-ministerio-publico-federal-foiperfeitamente-legal-afirma-procurador-da-lava-jato

${ }_{12}$ Página 19. http://www.esextante.com.br/media/upload/livros/Alutacontraacorrupcao_Trecho.pdf

${ }^{13}$ http://www.sanegraph.net.br/empresa/
} 
empresas públicas de Saneamento". Atendem muitas prefeituras.

\section{4 - Diogo Castor de Mattos}

Diogo Castor de Mattos, procurador. Filho do falecido procurador Delivar Tadeu de Mattos. Irmão de Rodrigo Castor de Mattos ${ }^{14}$ e Analice Castor de Mattos. Escritório Delivar de Mattos e Castor. "Os nomes dos irmãos são listados juntos em pelo menos cinco procedimentos judiciais que tramitam na $13^{\mathrm{a}}$ Vara Federal de Curitiba, comandada pelo juiz Sérgio Moro. De lados opostos: o primeiro como advogado de defesa e o segundo como membro do Ministério Público".

Sobrinho de Belmiro Valverde Jobim Castor, secretário de Estado, diretor do Bamerindus. Bisneto de Belmiro de Lima Valverde, chefe integralista nacional ${ }^{15}$.

\section{5 - João Pedro Gebran Neto}

João Pedro Gebran Neto. Filho de Antonio Sebastião da Cunha Gebran, diretor-geral da Assembleia Legislativa do Paraná. O avô paterno, João Pedro Gebran, também foi diretorgeral da Assembleia Legislativa do Paraná desde 1955, antes fora Diretor dos Serviços Legislativos e no Estado Novo foi Secretário do Conselho Administrativo do Paraná. O casamento de João Pedro Gebran, em 1924, é que abriu as portas da classe dominante tradicional paranaense. Fenômeno conhecido em que jovens de origem migrante, no caso do Oriente Médio, com potencial e bem sucedidos, casam com jovens das velhas famílias do "Antigo Regime", que assim se prolongam e cooptam os novos elementos. Gebran passou também a se relacionar com a poderosa e antiga rede social e política de sua esposa, Francisca Cunha, a Chiquinha, filha do Coronel Francisco Cunha, Prefeito da Lapa na República Velha (Genealogia Paranaense, IV, 390). O avô do Coronel Francisco Cunha foi o Comendador Manuel Antonio da Cunha, primeiro Prefeito da Lapa, em 1833, por sua vez casado com Joaquina Teixeira Coelho, filha do $1^{\circ}$ Capitão-Mor da Lapa, ainda no período Colonial, o português Francisco Teixeira Coelho. Todas essas famílias do poder local da Lapa, com origens históricas no latifúndio escravista, eram aparentadas entre si, a família Braga, do Governador Ney Braga, a familia Lacerda, do Reitor e Ministro da Educação no

\footnotetext{
${ }^{14}$ https://apublica.org/2018/05/de-cada-lado-do-balcao-um-castor-de-mattos/

15 http://www.delivardemattos.com.br/socio/rodrigo-castor-de-mattos/

http://www.fgv.br/cpdoc/acervo/dicionarios/verbete-biografico/belmiro-de-lima-valverde
} 
começo da Ditadura, Flávio Suplicy de Lacerda e outras. Como as mesmas famílias controlam o poder executivo, legislativo e judiciário ao longo de suas genealogias. Como a estrutura social do século XVIII é reproduzida e transmitida ao longo das gerações e dos casamentos. Como o antigo, arcaico e tradicional convive com o novo, moderno e as mudanças continuam e preservam a dinâmica social de exclusão do passado. Família política tradicional da Lapa.

Daniela Rache Gebran, advogada e esposa de João Pedro Gebran Neto. Rache \& Gebran Advogados Associados.

\section{6 - Victor Luiz dos Santos Laus}

Victor Luiz dos Santos Laus. O pai Linesio Laus é advogado. Laus Imoveis Assessoria e Planejamento Ltda - ME. O bisavô foi o Desembargador Domingos Pacheco D’Ávila.

“O empossando lembra que, por estes tempos, seu avô materno, Ernani Sayão dos Santos, com aguda premonição, costumava observar à filha Wanda que "este Victor me lembra muito meu sogro". O sogro, avô de Wanda, era o Desembargador Domingos Pacheco d'Ávila, oriundo

da tradicional Faculdade de Direito de Recife, co-fundador do Tribunal de Justiça de Santa Catarina, onde chegou com apenas 35 anos, e seu Presidente entre 1902 a 1910. Estava no sangue, mas demorou a aflorar. ${ }^{16,}$

\section{7 - Carlos Eduardo Thompson Flores Lenz}

Carlos Eduardo Thompson Flores Lenz. Presidente TRF4. Desembargador. Filho de Mariza Thompson Flores, diplomada em letras e professora de Inglês do Curso Médio, casada com o Dr. Otmar Lens, Juiz do Trabalho ${ }^{17}$. Neto do Ministro do STF Carlos Thompson Flores, a quem elaborou a genealogia: “Aos 26 de janeiro de 1911, há cem anos, nasceu Carlos Thompson Flores na cidade de Montenegro, no Estado do Rio Grande do Sul. Filho do político e advogado Luiz Carlos Reis Flores e de Dona Francisca Abbott Borges Fortes Flores, foram os seus avôs paternos o Desembargador Carlos Thompson Flores e Dona Luíza Elvira Reis Flores, filha do Barão de Camaquã, um dos comandantes militares da Guerra do

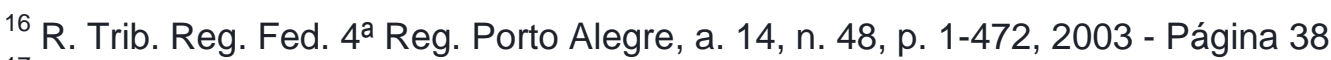

${ }^{17} \mathrm{http}: / / \mathrm{www}$. stf.jus.br/portal/ministro/verMinistro.asp?periodo=stf\&id=3
} 
Paraguai; pelo lado materno, o Dr. João Pereira da Silva Borges Fortes, político e magistrado no Império, e Dona Ofélia Abbott Borges Fortes, irmã do ex-Ministro da República e exgovernador, Dr. Fernando Abbott. O Ministro Carlos Thompson Flores é descendente de algumas das mais ilustres e antigas famílias do Brasil que forneceram ao nosso país políticos do mais alto relevo, como o Marechal Hermes Rodrigues da Fonseca, Presidente da República, diplomatas como o embaixador Carlos Martins Thompson Flores, médicos como o Conselheiro do Império Dr. Jonathas Abbott, considerado por muitos o maior luminar da ciência médica brasileira no século XIX. Destacam-se, ainda, o Coronel Thomaz Thompson Flores, herói da Guerra de Canudos, cujos feitos são relatados por Euclides da Cunha na obra clássica "Os Sertões"; o Ministro Francisco, Thompson Flores, Ministro do Tribunal de Contas da União que, em 1937, como relator das contas do Presidente. Getúlio Vargas, levou a Corte de Contas a manifestar-se pela rejeição das contas do Presidente da República, em decisão sem precedentes na história daquele Tribunal. É descendente direto do bandeirante Raposo Tavares, um dos fundadores do Brasil, e de Dionísio Rodrigues Mendes, um dos primeiros povoadores do Rio Grande do Sul, cuja fazenda, em meados do século XVIII, situava-se em terras onde hoje se localiza o Município de Porto Alegre. Uma das fazendas de seu bisavô, o Dr. João Pereira da Silva Borges Fortes, notável político do segundo reinado, hospedou o Imperador D. Pedro II e toda a sua comitiva, no ano de 1865, em São Gabriel, quando de sua visita à Província de São Pedro. Corre em suas veias o nobre sangue da família Leme, de São Paulo, que deu ao Brasil homens como o Cardeal D. Sebastião Leme,que desempenhou papel decisivo para o favorável desfecho da Revolução de 1930, ao convencer o Presidente deposto Washington Luís Pereira de Sousa a partir para o exílio. São, ainda, seus primos o Almirante Diogo Borges Fortes, Ministro e Presidente do Superior Tribunal Militar, o General Carlos Flores de Paiva Chaves, o primeiro militar brasileiro a comandar tropas da ONU-comandou a Faixa de Gaza nos anos cinquenta -, o Almirante Joaquim Flores do Rêgo Monteiro, formado em Engenharia Naval na Inglaterra e um dos pioneiros no país nessa importante modalidade de engenharia e o Embaixador Francisco Thompson Flores, um dos responsáveis pela criação e instalação do Mercosul, quando embaixador em Buenos Aires. Essas, em apertada síntese, são as origens familiares de Carlos Thompson Flores. O homem, disse-o Antonio Joaquim Ribas, em sua biografia de Campos Salles, é um ser sucessivo, cuja alma contém, algumas vezes, as virtudes de cem gerações. Como nos minerais e vegetais, prossegue o notável biógrafo, a natureza elabora, longa e surdamente, as suas obras-primas na humanidade. Eis por que assinalamos que nos seus antepassados já se revelavam as altas virtudes que, aperfeiçoadas pelo estudo e meditação, destinaram no às mais elevadas posições 
na administração da nossa Nação. A l'origine d'une vocation, recorda Roger Martín Du Gard, il y a presque toujours un exemple. No exemplo de seus ancestrais, colheu a inspiração e o estímulo que lhe serviram de motivação na escolha de sua vocação, a magistratura, cujo exercício consumiu toda a sua existência. ${ }^{18,}$

\section{8 - Felix Fischer}

Felix Fischer. Casado com a Procuradora aposentada Sonia Maria Bardelli Silva e pai dos seguintes magistrados: Desembargador pelo quinto Octavio Campos Fischer, juiz João Campos Fischer e juiz Fernando Bardelli Silva Fischer. "Estão registrados 88 processos de Denise Campos Fischer e Octávio Campos Fischer, filhos do ministro Felix Fischer"19.

\section{9 - Leonardo Bechara Stancioli}

Leonardo Bechara Stancioli, juiz. "O genro do ex-ministro do Superior Tribunal de Justiça (STJ) Paulo Medina, Leonardo Bechara Stancioli, tomou posse ontem no Tribunal de Justiça do Paraná (TJ-PR) como juiz substituto. A posse ocorreu mesmo com Stancioli ainda sendo investigado pelo Ministério Público do Paraná (MP) por supostamente ter sido favorecido num concurso do TJ-PR, em 2006. De um total de 1.748 escritos, Stancioli ficou em $17^{\circ}$ lugar.Em gravações feitas pela Polícia Federal durante a Operação Furacão, o então ministro Paulo Medina aparece dizendo que o esquema para que Stancioli passasse no concurso do TJPR estava montado. Medina pediu afastamento do STJ em maio de 2007, após as investigações da PF. Ele é acusado de vender sentenças favoráveis a um esquema de máfia de jogos ilegais ${ }^{20,}$.

O juiz Leonardo Bechara Stancioli, do Tribunal de Justiça do Estado do Paraná, passou a atuar como Juiz Auxiliar no Gabinete do Ministro Felix Fisher, relator dos processos da Lava-Jato no $\mathrm{STJ}^{21}$.

\footnotetext{
${ }^{18}$ Revista da Faculdade de Direito da UFRGS- n 29,2011 7. MINISTRO CARLOS THOMPSON FLORES. (Centenário do seu nascimento). Carlos Eduardo Thompson Flores Lenz Desembargador Federal do TRF/4a Região

${ }^{19} \mathrm{https}$ ///www1.folha.uol.com.br/poder/2016/04/1765552-dez-ministros-do-stj-tem-parentes-que-advogam-emcasos-no-tribunal.shtml http://www.sindijuspr.org.br/noticias/3/noticias/3906/ministro-felix-fischer-e-eleito-presidente-do-stj http://www.cjf.jus.br/cjf/noticias/2016-1/documentos-de-apoio/presidente-ministro-felix-fischer

${ }^{20} \mathrm{http}$ ://www.gazetadopovo.com.br/vida-publica/investigado-assume-como-juiz-bfqjaba10hw17t0un06bwvgwe

${ }^{21} \mathrm{https} / / /$ blogs.oglobo.globo.com/lauro-jardim/post/fischer-e-stancioli.html
} 


\section{0 - Luiz Edson Fachin}

Luiz Edson Fachin, ministro do STF. Casado com a desembargadora pelo quinto Rosana Amara Girardi Fachin. Pai de Melina Fachin casada com Marcos Alberto Gonçalves, filho de Marcos Gonçalves, executivo nas empresas da família Batista ${ }^{22}$.

"Criado pelo ministro do Supremo Tribunal Federal, Luiz Edson Fachin, nosso escritório preserva em seu DNA os princípios do seu fundador: "independentemente das posições pessoais, ter respeito ao sistema de regras, de princípios e de restrições, e a defender as garantias e os direitos individuais". Melina Girardi Fachin - sócia fundadora e Marcos Alberto Rocha Gonçalves. Escritório Fachin ${ }^{23}$.

\section{Circuito de Reivindicações dos Professores do Paraná}

1- Patrícia de Almeida Gomes Bergonse, juíza. Filha do juiz de direito aposentado Artur Heráclio Gomes Neto, Heráclio Gomes advogados associados com Guilherme de Almeida Gomes. Neta do desembargador do Tribunal de Justiça do Paraná e professor da Faculdade de Direito da Universidade Federal do Paraná, Artur Heráclio Gomes Filho, casado com Nelma de Loyola, de importante família ervateira do Paraná, Genealogia Paranaense, I-226. Nelma era filha do major João Pedro de Loyola e de Maria Rosa.

“A Justiça entendeu que o governador Beto Richa não foi o responsável pelos confrontos no dia 29 de abril de 2015, em Curitiba. A juíza da $5^{\text {a }}$ Vara da Fazenda Pública, Patrícia de Almeida Gomes Bergonse, decidiu que os manifestantes foram os culpados pela confusão que terminou com 200 pessoas feridas ${ }^{24}$."

2 - Antonio Loyola Vieira, desembargador. Filho de Joubert Gonzaga Vieira, promotor de justiça, prefeito de Antonina, Paraná, entre 1973-77 e 83-88, pelo PDS e de Eraylde Loyola

\footnotetext{
${ }^{22}$ https://www1.folha.uol.com.br/poder/2017/07/1898852-sogro-de-filha-de-fachin-e-chefe-em-empresa-dafamilia-batista.shtml https://www.tjpr.jus.br/desembargadores-tjpr-museu/-/asset_publisher/V8xr/content/des-rosana-amara-girardifachin/397262?inheritRedirect=false

${ }_{23}^{23}$ https://www.fachinadvogados.com.br/

${ }^{24} \mathrm{https} / / /$ pr.ricmais.com.br/politica/noticias/justica-absolve-richa-por-confronto-entre-professores-e-pms-emcuritiba/
} 
(Genealogia Paranaense: I, 226 e III, 356). Neto materno de Percival Loyola, juiz de direito e de Anita Romero. Percival era filho do major João Pedro de Loyola e de Maria Rosa.

"Na sessão do TJ-PR de 17 de julho, a votação havia terminado empatada, com 11 votos favoráveis e 11 contrários. Na ocasião, o desembargador Antônio Renato Strapasson apresentou pedido de vistas e a decisão foi transferida. Nesta segunda-feira, Strapasson anunciou voto favorável ao pleito dos educadores/as, o $12^{\circ}$, mas o desembargador Antônio Loyola Vieira, que não participou da sessão anterior, apresentou novo pedido de vistas ${ }^{25}$ ".

3 - Ruy Cunha Sobrinho, desembargador. Filho de Renato Cunha, que foi vereador e presidente da Câmara de Londrina. Ruy Cunha Sobrinho é casado com a procuradora do Estado Vera Grace Paranaguá, filha do falecido ex-prefeito de Londrina Dalton Paranaguá. O casal recebe bem do Estado e pode pensar nos pobres professores, que não ganham nem auxílio-moradia. Ruy Cunha Sobrinho recebeu o nome do seu tio Ruy Cunha, que foi deputado estadual eleito em 1947. Neto de Eurides Cunha, deputado estadual, deputado federal, prefeito de Jaguariaíva e de Curitiba no fim da República Velha. Todos formados em direito e grandes proprietários. Bisneto do Coronel Domingos Antonio da Cunha citado na Monografia (UFPR: 2016, 62) de Mariana Coelho Maximino - Ex-Senhores de Escravos, Elites e Negros Livres no Paraná do Imediato Pós-Abolição: ““Em comissão de Campo Largo aparece Domingos Antonio da Cunha, que teve 12 escravizados. Domingos Antonio da Cunha, foi deputado liberal por Campo Largo em 1880/81, 82/83, 84/85, $86 / 87$ e industrial do mate, também aparece congratulando a proclamação da República. Mostrando a posição de um ex-senhor de escravo, de uma elite escravista por possuir muitos escravos, que conseguiu se perpetuar na vida social e política durante o período Republicano".

"Quando o desembargador Ruy Cunha Sobrinho criticou os servidores públicos, dizendo que alguns forjam atestados e que mesmo com remuneração mais baixa por hora-atividade as escolas particulares eram melhores, os professores viraram de costas para o plenário ${ }^{26 "}$.

4- Ernani Mendes Silva Filho. Desembargador Ernani Mendes Silva. Genealogia de tradição da Lapa e citado na Genealogia Paranaense, de Francisco Negrão, III, 57.

\footnotetext{
${ }^{25} \mathrm{https}$ ://www.appfoz.com.br/noticias/hora-atividade-justica-vai-deixando-para-depois/ http://amapar.com.br/noticia-rss/item/desembargador-ant\%C3\%B4nio-loyola-fala-\%C3\%A0-amapar-sobre-50anos-de-judici\%C3\%A1rio-rela\%C3\%A7\% $3 \%$ A3o-com-o-executivo-e-elei\%C3\%A7\%C3\%B5es-dac\%C3\%BApula-2.html

${ }^{26} \mathrm{https}: / /$ www.gazetadopovo.com.br/politica/parana/em-meio-a-protesto-de-professores-discussao-sobre-horaatividade-e-adiada-no-tj-1 wpomx3sjvkx9or5dzkrh0atc
} 
“Cuida-se de interdito proibitório proposto por Município de Curitiba/PR contra Movimentos e outros. Alega o autor, em suma, que em razão do mandado de prisão expedido em face do ex-Presidente da República, Luiz Inácio Lula da Silva, será realizada sua transferência para a sede da Polícia Federal localizada no Santa Cândida, neste Município.

Sustenta que no local já se verifica aglomeração de pessoas e movimentos, o que pode ocasionar transtornos aos moradores da região e grave lesão à ordem e segurança públicas ${ }^{27}$." "Manifestantes foram agredidos por policiais em frente à sede da Polícia Federal de Curitiba, na noite deste sábado (7). O tumulto aconteceu no momento da chegada do ex-presidente Lula à PF e foi flagrado pela equipe do RedeTV News ${ }^{28 \%}$.

6 - Renato Braga Bettega, desembargador e atual Presidente do Tribunal de Justiça do Paraná. Filho do médico João Luiz Bettega e sobrinho materno do senador Rubens de Mello Braga e do médico Homero de Mello Braga, um dos fundadores da faculdade de Filosofia e Ciências da Universidade do Paraná ${ }^{29}$. A família Bettega, da imigração italiana, também já teve Lydio Paulo Bettega, o segundo presidente a assumir a Federação das Indústrias do Estado do Paraná - Fiep (1958 a 1968).

Podemos observar a importância da hereditariedade, das relações de parentesco, das genealogias e das redes sociais e profissionais nos atores investigados. Os emergentes, os "parvenus", que ainda não possuíam as redes familiares no campo político-jurídico, passam a formá-las, assim que sobrem nas carreiras e nos cargos de poder, reproduzindo o comportamento e as estruturas dos estabelecidos. Concluímos com as mesmas observações ao finalizarmos a nossa tese de doutorado e o livro "O Silêncio dos Vencedores". Como instituições pré-modernas e estruturas familiares, com origens culturais muitas vezes no passado, cooptam novas famílias emergentes no seu ethos e práticas políticas, representando a continuidade do arcaico sob falsas roupagens do novo, para preservarem o status quo e a desigualdade da velha ordem social. Tal como no poder executivo e no legislativo, só

\footnotetext{
${ }^{27}$ PROJUDI - Processo: 0008301-46.2018.8.16.0013 - Ref. mov. 5.1 - Assinado digitalmente por Ernani Mendes Silva Filho:15395 
entenderemos o judiciário e suas indicações políticas, suas preferências ideológicas, suas orientações e suas práticas político-jurídicas, conhecendo também as suas unidades familiares e genealógicas de poder. Assim caminha a "República do Nepotismo".

\section{Genealogias Políticas do Judiciário}

\begin{tabular}{|c|c|c|}
\hline Nome & Parentescos ou redes sociais & Cargo/ Função \\
\hline Sérgio Moro & $\begin{array}{l}\text { Desembargador Hildebrando } \\
\text { Moro } \\
\text { Esposa - Rosangela Maria } \\
\text { Wolff Quadros, advogada. } \\
\text { Reitor Neumar Godoy } \\
\text { Zucolotto Advogados }\end{array}$ & Juiz da lava jato \\
\hline Rosangela Wolff Quadros & $\begin{array}{l}\text { Desembargador Haroldo } \\
\text { Bernardo da Silva Wolff } \\
\text { Fernando Paulino da Silva } \\
\text { Wolff Filho } \\
\text { Clã Macedo }\end{array}$ & Esposa do juiz Moro \\
\hline Marlus Arns de Oliveira & $\begin{array}{l}\text { Flavio Arns, tio materno } \\
\text { Promotor Luiz Carlos de } \\
\text { Oliveira, pai }\end{array}$ & Advogado \\
\hline $\begin{array}{l}\text { Carlos Fernando dos Santos } \\
\text { Lima }\end{array}$ & $\begin{array}{l}\text { Procurador Osvaldo dos Santos } \\
\text { Lima. Deputado estadual. } \\
\text { Presidente da ALEP em 1973, } \\
\text { pai. } \\
\text { Luiz José - MP } \\
\text { Paulo Ovídio - MP. } \\
\text { Osvaldo - UFPR } \\
\text { Vera Lucia Ribas de Macedo }\end{array}$ & Procurador MPF \\
\hline Deltan Martinazzo Dallagnol & $\begin{array}{l}\text { Procurador Agenor Dallagnol } \\
\text { pai. } \\
\text { Fernanda Mourão Ribeiro, } \\
\text { esposa, advogada, sócia da } \\
\text { Sanegraph }\end{array}$ & Procurador MPF \\
\hline Diogo Castor de Mattos & $\begin{array}{l}\text { Procurador Delivar Tadeu de } \\
\text { Mattos, pai. } \\
\text { Advogados Rodrigo Castor de } \\
\text { Mattos, irmão. Analice Castor } \\
\text { de Mattos, irmã. } \\
\text { Belmiro Valverde Jobim } \\
\text { Castor, tio. }\end{array}$ & Procurador MPF \\
\hline João Pedro Gebran Neto & $\begin{array}{l}\text { Antonio Sebastião da Cunha, } \\
\text { pai } \\
\text { Daniela Rache Gebran, }\end{array}$ & Desembargador TRF4 \\
\hline
\end{tabular}




\begin{tabular}{|c|c|c|}
\hline & advogada, esposa & \\
\hline Victor Luiz dos Santos Laus & $\begin{array}{l}\text { Bisavô Desembargador } \\
\text { Domingos Pacheco D'Ávila }\end{array}$ & Desembargador TRF4 \\
\hline $\begin{array}{l}\text { Carlos Eduardo Thompson } \\
\text { Flores Lenz }\end{array}$ & Genealogia Thompson Flores & $\begin{array}{l}\text { Presidente TRF4 } \\
\text { Desembargador }\end{array}$ \\
\hline Felix Fischer & $\begin{array}{l}\text { Procuradora Sonia Maria } \\
\text { Bardelli Silva, esposa } \\
\text { Filhos: Desembargador } \\
\text { Octavio Campos Fischer } \\
\text { João Campos Fischer, juiz } \\
\text { Fernando Bardelli Silva } \\
\text { Fischer, juiz }\end{array}$ & STJ \\
\hline Leonardo Bechara Stancioli & $\begin{array}{l}\text { Genro do ministro Paulo } \\
\text { Medina do STJ }\end{array}$ & Juiz TJ-PR e STJ \\
\hline Edson Fachin & $\begin{array}{l}\text { Desembargadora Rosana } \\
\text { Amara Girardi Fachin } \\
\text { Filha, Melina Fachin, } \\
\text { advogada, c.c. Marcos Alberto } \\
\text { Gonçalves, filho de Marcos } \\
\text { Gonçalves. }\end{array}$ & STF \\
\hline $\begin{array}{l}\text { Patricia de Almeida Gomes } \\
\text { Bergonse }\end{array}$ & $\begin{array}{l}\text { Filha do juiz de direito } \\
\text { aposentado Artur Heráclio } \\
\text { Gomes Neto, Heráclio Gomes } \\
\text { advogados associados. Neta do } \\
\text { desembargador do Tribunal de } \\
\text { Justiça do Paraná e professor } \\
\text { da Faculdade de Direito da } \\
\text { Universidade Federal do } \\
\text { Paraná, Artur Heráclio Gomes } \\
\text { Filho, casado com Nelma de } \\
\text { Loyola, de importante família } \\
\text { ervateira do Paraná, Genealogia } \\
\text { Paranaense, I-226 }\end{array}$ & Juíza \\
\hline Ruy Cunha Sobrinho & $\begin{array}{l}\text { Filho de Renato Cunha, que foi } \\
\text { vereador e presidente da } \\
\text { Câmara de Londrina. Ruy } \\
\text { Cunha Sobrinho é casado com } \\
\text { a procuradora do Estado Vera } \\
\text { Grace Paranaguá, filha do } \\
\text { falecido ex-prefeito de } \\
\text { Londrina Dalton Paranaguá. } \\
\text { Ruy Cunha Sobrinho recebeu o } \\
\text { nome do seu tio Ruy Cunha, } \\
\text { deputado estadual eleito em } \\
\text { 1947. Neto de Eurides Cunha, } \\
\text { deputado estadual, deputado } \\
\text { federal, prefeito de Jaguariaíva } \\
\text { e de Curitiba no fim da }\end{array}$ & Desembargador \\
\hline
\end{tabular}




\begin{tabular}{|l|l|l|}
\hline & $\begin{array}{l}\text { República Velha. Bisneto do } \\
\text { Coronel Domingos Antonio da } \\
\text { Cunha }\end{array}$ & \\
\hline Antonio Loyola Vieira & $\begin{array}{l}\text { Filho de Joubert Gonzaga } \\
\text { Vieira, promotor de justiça, } \\
\text { prefeito de Antonina, Paraná, } \\
\text { entre 1973-77 e 83-88, pelo } \\
\text { PDS e de Eraylde Loyola } \\
\text { (Genealogia Paranaense: I, 226 } \\
\text { e III, 356). Neto materno de } \\
\text { Percival Loyola, juiz de direito } \\
\text { e de Anita Romero. }\end{array}$ & Desembargador \\
\hline Ernani Mendes Silva Filho & $\begin{array}{l}\text { Filho do Desembargador } \\
\text { Ernani Mendes Silva } \\
\text { Tradição da Lapa e da } \\
\text { Genealogia Paranaense, de } \\
\text { Francisco Negrão,III, 577 }\end{array}$ & Juiz \\
\hline Renato Braga Bettega & $\begin{array}{l}\text { Família Bettega e sobrinho do } \\
\text { senador Rubens de Mello } \\
\text { Braga }\end{array}$ & $\begin{array}{l}\text { Desembargador e Presidente do } \\
\text { Tribunal de Justiça do Paraná. }\end{array}$ \\
\hline
\end{tabular}

Fonte: O Autor. 